\title{
Investigation of static and fatigue crack growth mechanism of borated stainless steel using in situ observation method
}

\author{
Shota HASUNUMA*, Keita SUGAWARA** and Takeshi OGAWA* \\ *Department of Mechanical Engineering, Aoyama Gakuin University \\ 5-10-1 Fuchinobe, Chuo-ku, Sagamihara-shi, Kanagawa 252-5258, Japan \\ E-mail: hasunuma@me.aoyama.ac.jp \\ **Graduate School of Mechanical Engineering, Aoyama Gakuin University \\ 5-10-1 Fuchinobe, Chuo-ku, Sagamihara-shi, Kanagawa 252-5258, Japan
}

Received: 20 February 2019; Revised: 21 May 2019; Accepted: 26 May 2019

\begin{abstract}
The borated stainless steel B-SUS304P-1 is used for storage and transport metal casks in the nuclear industry. According to our previous research, the boron addition reduces the fracture toughness but has a minimal effect on the fatigue crack growth. In this study, in situ laser microscopy observation during tensile, fracture toughness and fatigue crack growth tests of B-SUS304P-1 was performed to investigate the mechanism responsible for the effects of the boron addition on static and fatigue crack growth. During the tensile test, the borides were broken, but the base material remained intact. Results obtained using the digital image correlation method revealed that the strain of boride at fracture was very low compared with the macroscopic elongation of B-SUS304P-1. For the fracture toughness test, the borides in front of the crack were broken before static crack growth. The crack propagated along a zigzag path as it grew along the broken borides. Because of this crack growth mechanism, the fracture toughness was reduced by the boron addition. In contrast, for the fatigue crack growth test, only a few broken borides were observed in front of the crack because the stress intensity factor of the fatigue test was smaller than that of the fracture toughness test. The crack thus grew linearly, and the boron addition had a minimal effect on the fatigue crack growth of the stainless steel.
\end{abstract}

Keywords: Fracture toughness, Fatigue crack growth, Austenitic stainless steel, Boride, In situ observation

\section{Introduction}

The borated stainless steel B-SUS304P-1 (B-SUS) is used for storage and transport metal casks in the nuclear industry. B-SUS is used for the plates of the grid structure of the basket used to store fuel (Doumori et al., 2010). In our previous study, we investigated the fatigue crack growth characteristics (upper bound characteristics of fatigue crack growth and fracture toughness) of B-SUS in comparison with those of the austenitic stainless steel SUS316 (Miyai et al, 2016). The effect of boron addition on the crack growth was also investigated. According to our previous study, the effect of boron addition on fatigue crack growth with a very low load condition from fracture toughness is small; however, the static fracture residence is reduced by boron addition. Observation of the fracture surface revealed that the area ratio of boride on the fracture surface for toughness tests was larger than that for fatigue tests (Hasunuma et al, 2018). Therefore, for the fracture toughness tests, the brittle boride was assumed to be broken in front of the crack, and the crack was assumed to propagate along the broken borides, thereby explaining the reduction of the fracture toughness by the boron addition. However, this conjecture was made from observation of the fracture surface alone without direct observation of the propagation mechanism. Direct observation of the deformation and fracture behavior of borides during crack growth tests is critical to determine the mechanism of crack growth. For example, the effect of inclusion particles on the fracture of aluminum alloy was investigated using in situ scanning electron microscopy (Takahashi et al., 1999; Toda et al., 2001). In addition, fatigue crack initiation from inclusion particles of a nickel-based superalloy was observed using in situ scanning electron microscopy, and the mechanism of crack initiation was investigated (Huang et al., 2012). 
In this study, the mechanism of the effect of boron addition on static and fatigue crack growth for B-SUS was investigated using in situ laser microscopy during fracture toughness and fatigue crack growth tests. Then, the fracture behavior of the boride and the crack growth behavior were directly observed. In addition, the strain when the boride was broken was determined using the digital image correlation (DIC) method for the tensile tests. Finally, the mechanisms of the effect of boron addition on static and fatigue crack growth were investigated.

\section{Material and experimental procedures}

\subsection{Material and specimen}

The chemical composition and mechanical properties of the B-SUS used in this study are shown in Table 1 and 2, and the microstructure of B-SUS is shown in Fig. 1. The T and L directions in Fig. 1 indicate the transverse and longitudinal directions, respectively. The borides are indicated by the red arrows. Figure 2 shows the specimen shape. A single-edge-notched specimen (width $W=6.4 \mathrm{~mm}$, thickness $B=0.8 \mathrm{~mm}$, notch length $=3.5 \mathrm{~mm}$, and radius of notch tip $=250 \mu \mathrm{m}$ ) was used in this study. The crack growth and loading directions were along the transverse and longitudinal directions, respectively. The preparation procedure is explained in Fig. 3. The material was first cut into a cuboid with dimensions of $18 \mathrm{~mm} \times$ optional length $\times 6.4 \mathrm{~mm}$. Next, the notch was introduced by wire cut. Third, drilling was performed to introduce a hole, which was used to fix the specimen to the testing machine. Finally, the material was cut to a thickness of $0.8 \mathrm{~mm}$ by wire cut. The specimen surfaces were polished with colloidal silica (particle size $=0.04$ $\mu \mathrm{m}$ ) after diamond-suspension polishing (abrasive grain sizes of 9, 3, and $1 \mu \mathrm{m}$ ). The specimen thickness was reduced to approximately $0.5-0.7 \mathrm{~mm}$ by this polishing procedure.

\subsection{Testing machine}

Figure 4 presents photographs and a schematic illustration of the testing machine developed in-house and its components. A photograph of the testing machine is presented in Fig. 4(a). The testing machine was constructed using a

Table 1 Chemical composition (mass\%).

\begin{tabular}{cccccccccc}
\hline $\mathrm{C}$ & $\mathrm{Si}$ & $\mathrm{Mn}$ & $\mathrm{P}$ & $\mathrm{S}$ & $\mathrm{Ni}$ & $\mathrm{Cr}$ & $\mathrm{B}$ & $\mathrm{Mo}$ & $\mathrm{Fe}$ \\
\hline 0.03 & 0.64 & 0.98 & 0.02 & 0.001 & 8.4 & 19.26 & 1.06 & - & $\mathrm{BAL}$. \\
\hline
\end{tabular}

Table 2 Mechanical properties.

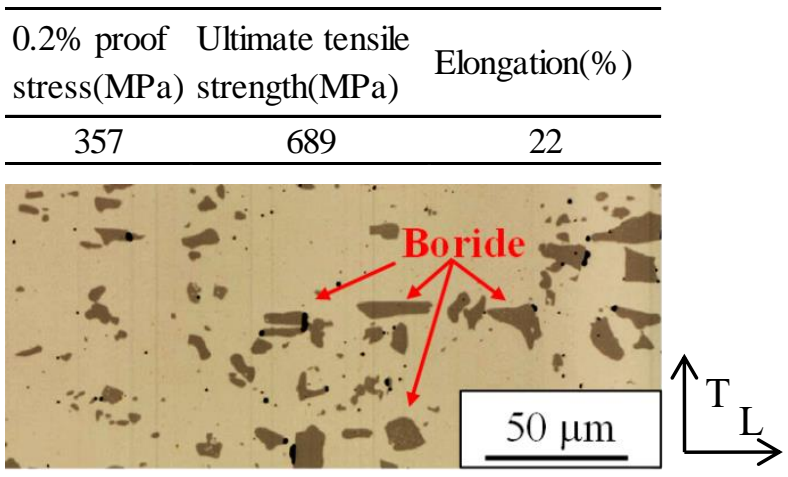

Fig. 1 Micro structure of B-SUS. The Arrows indicate boride.

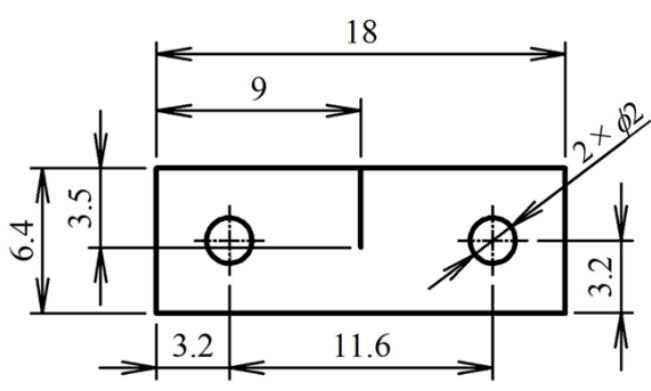

t0.8
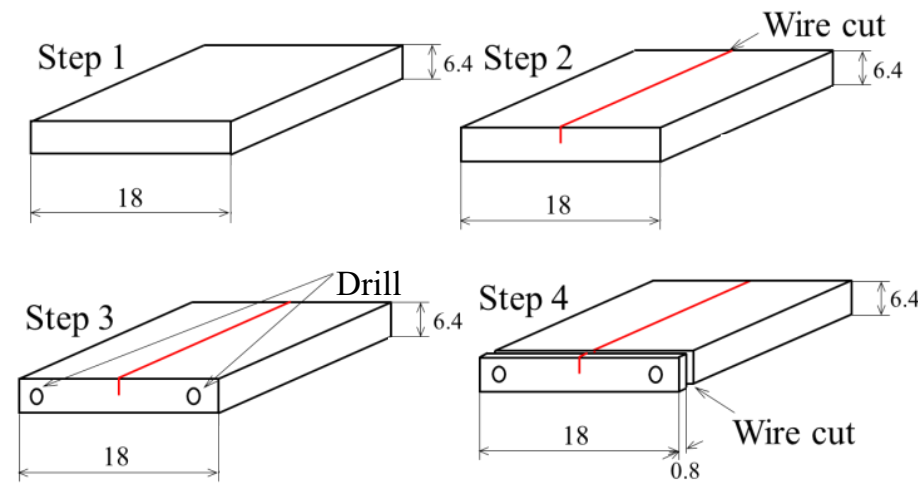

Fig. 3 Method of preparing specimen. 
load cell (TCLS-50, Tokyo Measuring Instruments Lab., Tokyo, Japan), fixture, linear guide, stroke head, ball screw, coupling and motor (AR24, Oriental motor, Tokyo, Japan). The motor and ball screw were connected by a coupling, allowing the power of the motor to be transmitted to the ball screw. A bi-directional ball screw was used in this study; thus, the two stroke heads moved in opposite directions. Details of fixture (4) in Fig. 4(a) are shown in Fig 4(b). The blue opaque part was fixed to the stroke head, and pins were used to connect the translucent part to the blue opaque part. Grease was applied to the pins to reduce the friction. Fig. 4(c) presents a photograph of the load cell, which was fixed to the fixture by a full-thread bolt and nut.

\subsection{Experimental procedure}

Tensile, fracture toughness, and fatigue crack growth tests were performed in this study. To observe the fracture behavior of the borides and the crack growth behavior, the testing machine described in section 2.2 was placed on the stage of an Optelics Hybrid scanning laser microscope (Lasertec Co., Kanagawa, Japan), and then, the experiments were performed.

For the tensile test, a tensile load was applied to the notched specimen shown in Fig. 2, and the strain distribution in front of the notch was measured using the DIC method (Yoneyama, 2014). The stroke head moved with constant velocity. The stroke head was stopped at selected times, and an image in front of the notch was captured. An image of the area near the notch is presented in Fig. 5. We measured the strain distribution in the $880 \times 470$ pixel region enclosed by the dashed rectangle using the DIC method. The subset size was $25 \times 25$ pixels. The random pattern was created by molybdenum disulfide. The tensile test was completed after the load $P$ reached $270 \mathrm{~N}$. Then, the random pattern was removed, and the specimen surface was examined to determine the relationship between the presence of boride (or broken boride) and the strain.

For the fracture toughness test, the stroke head moved with constant velocity; then, the testing load was applied until fracture. The stroke head was stopped at selected times, and an image of the crack tip was captured. Before the fracture toughness test, a fatigue precrack was introduced with a length of approximately $4 \mathrm{~mm}$ under constant load range $\Delta P$ conditions. While introducing the precrack, the stroke head was feedback-controlled based on the load monitored by the load cell. A maximum load $P_{\max }=100 \mathrm{~N}$ and minimum load $P_{\min }=10 \mathrm{~N}$ were used for introducing the precrack.

The fatigue crack growth test was performed under constant $\Delta P$ conditions. Therefore, the stress intensity factor range, $\Delta K$, increased with increasing crack length, a. $P_{\max }=85 \mathrm{~N}$ and $P_{\min }=8.5 \mathrm{~N}$ were used for the fatigue crack growth test. The part of the crack that was shorter than $a=4 \mathrm{~mm}$ was regarded as the precrack, and the crack growth was evaluated after $a=4 \mathrm{~mm}$. We stopped the stroke head at select cycles and captured an image of the crack tip. The
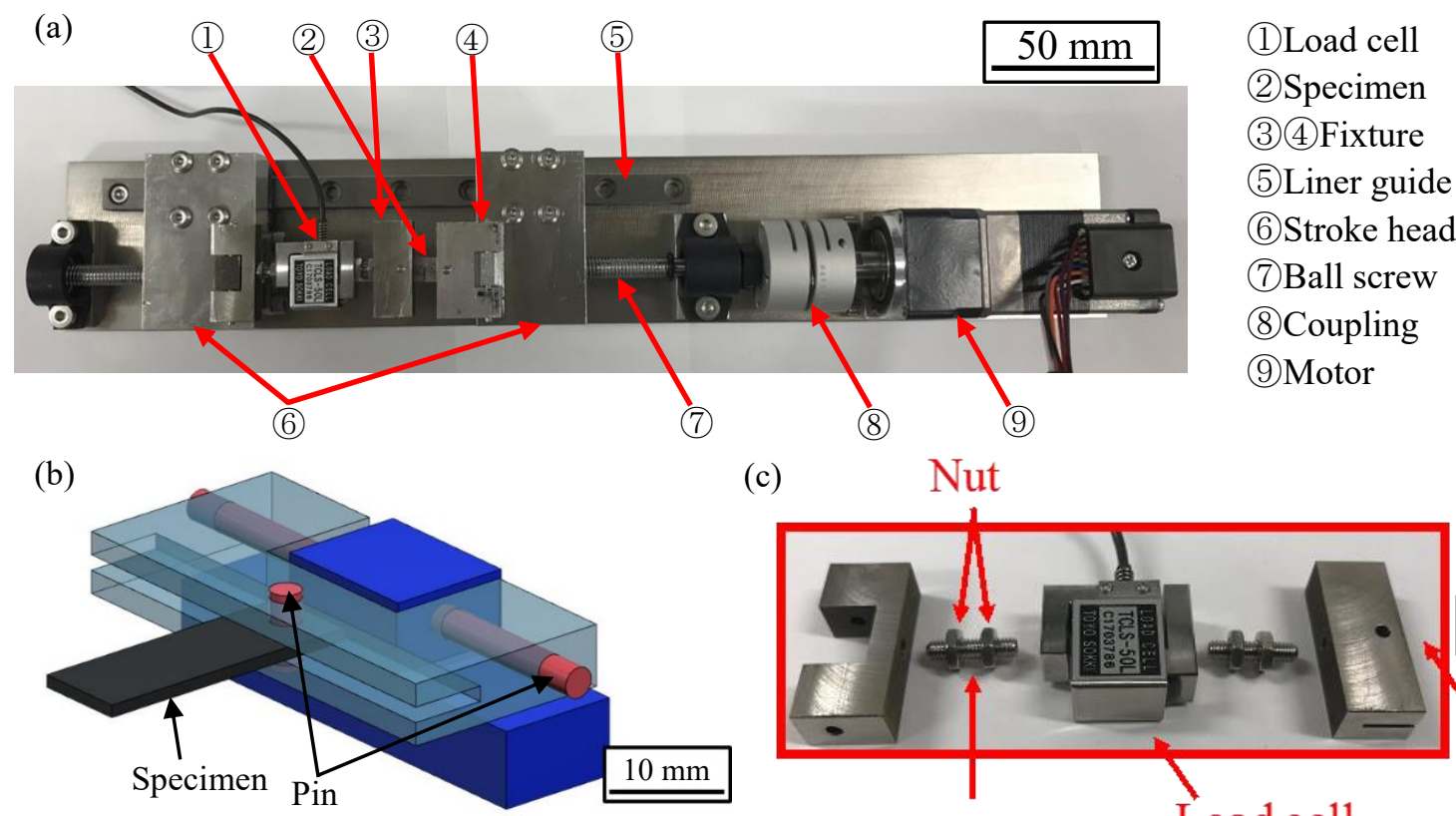

(c)

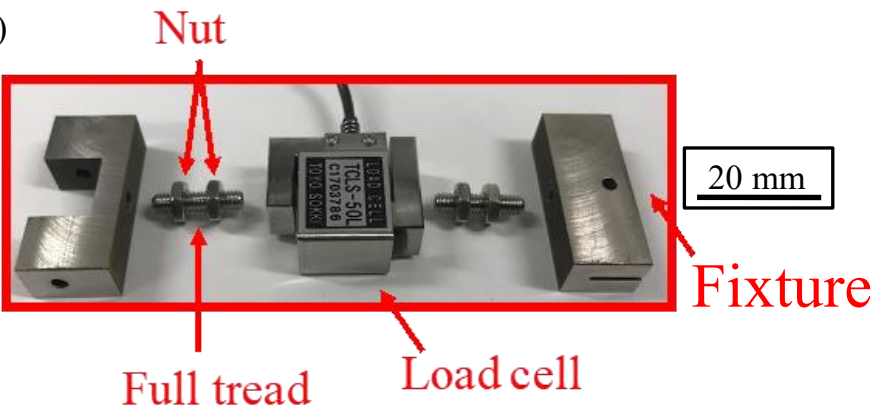

Fig.4 Photograph of testing machine (a), detailed illustration of fixture (4) (b), and photograph of the load cell (c). 
crack length was determined from the captured image. The stress intensity factor, $K$, was calculated using Eq. (1) and (2).

$$
\begin{aligned}
& K=\frac{P}{B \sqrt{W}} f(a / W) \\
& f(a / W)=\left[\frac{1}{2}\left(835266(a / W)^{5}-2557945(a / W)^{4}+3147100(a / W)^{3}-1940874(a / W)^{2}+599470(a / W)-74132\right)\right]^{\frac{1}{2}}
\end{aligned}
$$

These equations are based on finite element analysis, which was performed using the same model as the specimen shown in Fig. 2. After the precrack was introduced, $\Delta K$ was $9.93 \mathrm{MPa} \sqrt{\mathrm{m}}$, respectively.

\section{Results}

\subsection{Tensile test}

Figure 6 shows the specimen surface and $x$-direction strain distribution for the region enclosed by the dashed rectangle in Fig. 5 after a load of $P=270 \mathrm{~N}$ was applied. Figure 6(a) shows the specimen surface after the random pattern was removed. There were no large changes in the base material. However, many cracked borides were observed. The distribution of the $x$-direction strain, $\varepsilon_{x}$, superposed on Fig. 6(a) is shown in Fig. 6(b). The strain increased closer to the notch. In addition, the strain was large in the area in which boride was cracked because of crack opening. The strain in an area containing cracked boride was compared with that in an area without cracked boride. Figure 7 shows the variation of the $x$-direction strain in the areas enclosed by the rectangles in Fig. 6(b). Areas 1 and 2 included cracked boride, and areas 1' and 2' were near areas 1 and 2, respectively, but did not contain cracked boride. The plot in Fig. 7 shows the average of the $x$-direction strain in the rectangular areas of Fig. 6(b). For small applied load, there was no difference in the strain between the areas with and without cracked boride. However, for large applied load, the strain in the area containing cracked boride was larger than that in the area without cracked boride. The boride was broken at $\varepsilon_{\mathrm{x}}=0.4 \%$ and $0.3 \%$ in areas 1 and 2 , respectively. These strain values are very low compared with the macroscopic elongation values of B-SUS shown in Table 2 . The boride was thought to be broken immediately after macroscopic yielding.

\subsection{Fracture toughness test}

The relationship between the load and stroke head displacement is shown in Fig. 8. The left, right, and horizontal axis correspond to the load, stress intensity factor, and stroke head displacement, $d$, respectively. Note that small-scale yielding condition is not satisfied in this test. However, the apparent $K$ values are shown in order to compare the result

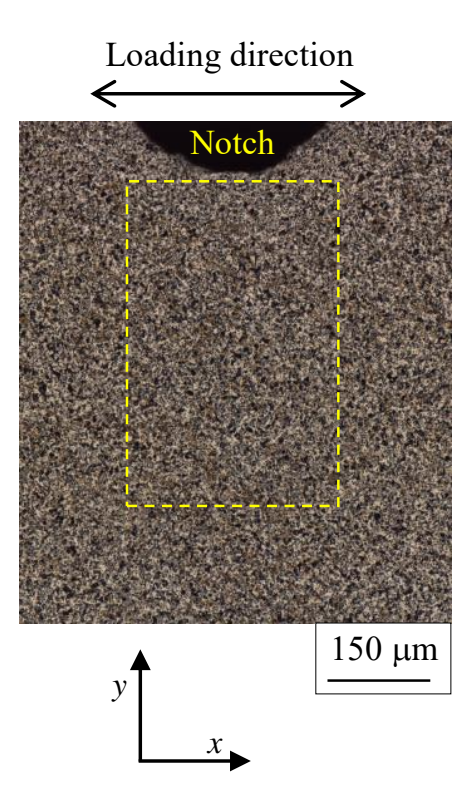

Fig. 5 Image of area near the notch.
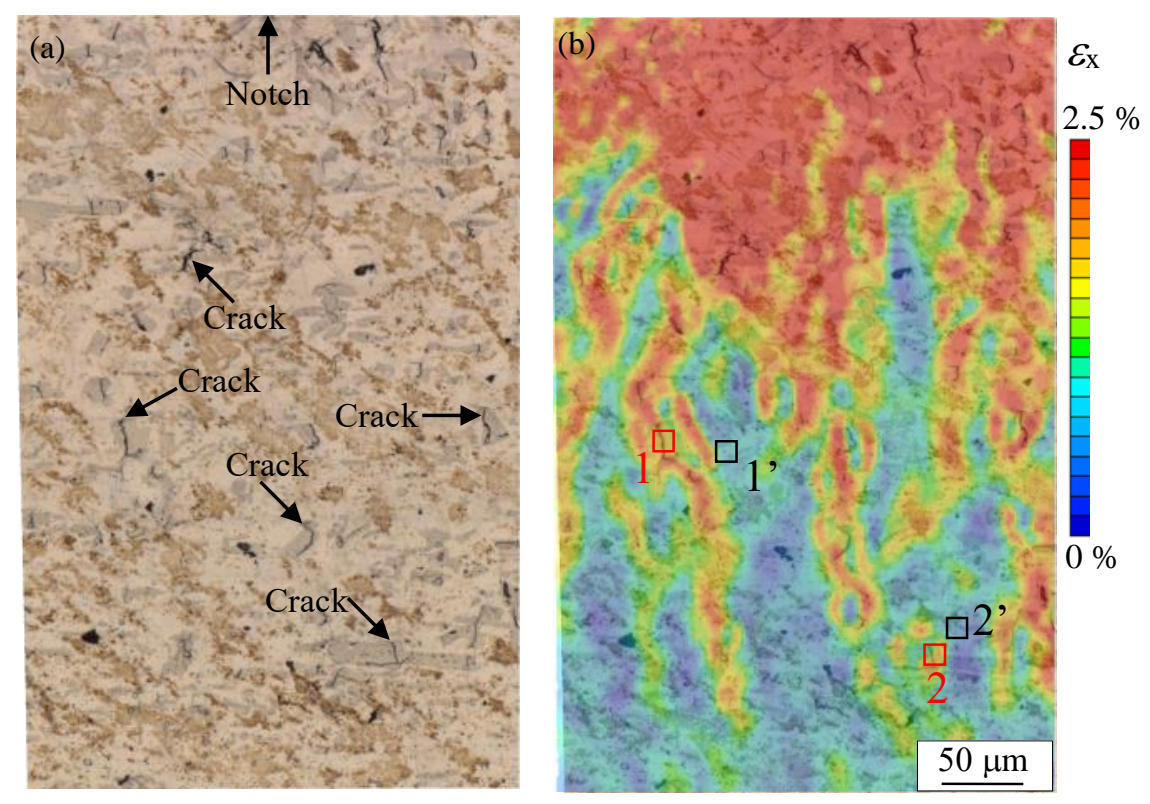

Fig. 6 Specimen surface (a) and $x$-direction strain distribution (b) after tensile test. The strain near the notch was very large and that near the crack was large. 
of our previous work (Miyai et al, 2016). The load rapidly decreased after reaching a peak at approximately $256 \mathrm{~N}$. After this, the load gradually decreased, and then, the specimen fractured. The stress intensity factor directly before the load drop was approximately $30 \mathrm{MPa} \sqrt{\mathrm{m}}$. This value is smaller than the fracture toughness $K_{\mathrm{c}}$, approximately 55 $\mathrm{MPa} \sqrt{\mathrm{m}}$, which was converted from elastic part of $\mathrm{J}$ integral, $J_{\mathrm{e}}$ (Miyai et al, 2016). This fracture toughness test followed ASTM E1820 standard and a compact tension (CT) specimen ( $B=6.4 \mathrm{~mm}, W=25$ or $50 \mathrm{~mm})$ was used (American Society for Testing and Materials). The reason for this difference is thought to be the effect of plastic collapse. The ligament yielding parameter $L_{\mathrm{r}}$ and plastic collapse limit $L_{\mathrm{r}}^{\max }$ were determined using Eq. (3) and (4), respectively (Kozokenzensei hyouka handbook henshuiinkai, 2005).

$$
\begin{aligned}
& L_{\mathrm{r}}=\frac{\lambda \sigma_{\mathrm{m}}+\frac{\sigma_{\mathrm{b}}}{3}+\sqrt{\left\{\left(\lambda \sigma_{\mathrm{m}}+\frac{\sigma_{\mathrm{b}}}{3}\right)^{2}+(1-\lambda)^{2} \sigma_{\mathrm{m}}^{2}\right\}}}{(1-\lambda)^{2} \sigma_{\mathrm{Y}}} \\
& L_{\mathrm{r}}^{\max }=\frac{\sigma_{\mathrm{f}}}{\sigma_{\mathrm{Y}}}
\end{aligned}
$$

Here, $\lambda=a / W$, the membrane stress $\sigma_{\mathrm{m}}=P /(W B)$, and the bending stress $\sigma_{\mathrm{b}}=6 M /\left(W^{2} B\right)$. $M$ is the moment, which was calculated using the crack tip as the center of rotation. The flow stress $\sigma_{\mathrm{f}}$ is the average of the tensile stress and $0.2 \%$ proof stress. We used the $0.2 \%$ proof stress for the yield stress $\sigma_{\mathrm{Y}}$. The calculated results for $L_{\mathrm{r}}$ and $L_{\mathrm{r}}^{\max }$ indicate that $L_{\mathrm{r}}$ became larger than $L_{\mathrm{r}}^{\max }$ for $P>159 \mathrm{~N}$. Therefore, plastic collapse reduced the $K$ value at fracture.

Figure 9 presents the crack observation results. The points at which the images were captured are indicated by the labels (a)-(c) in Fig. 8. Figure 9(a), (b), and (c) present photographs of the crack initiated from the notch, and Fig. 9(d), (e), and (f) present close-up images of the crack tip. Figure 9(b) shows blunting and opening of the crack tip at $P=244$ $\mathrm{N}$. Then, there were many broken borides and slip in front of the crack tip. At $P=182 \mathrm{~N}$ (after the load decreased), the crack propagated greatly, as shown in Fig. 9(c). Although the results in this study were affected by plastic collapse, static crack growth was observed. Comparison of Figs. 9(e) and (f) reveals that the crack propagated along a zigzag
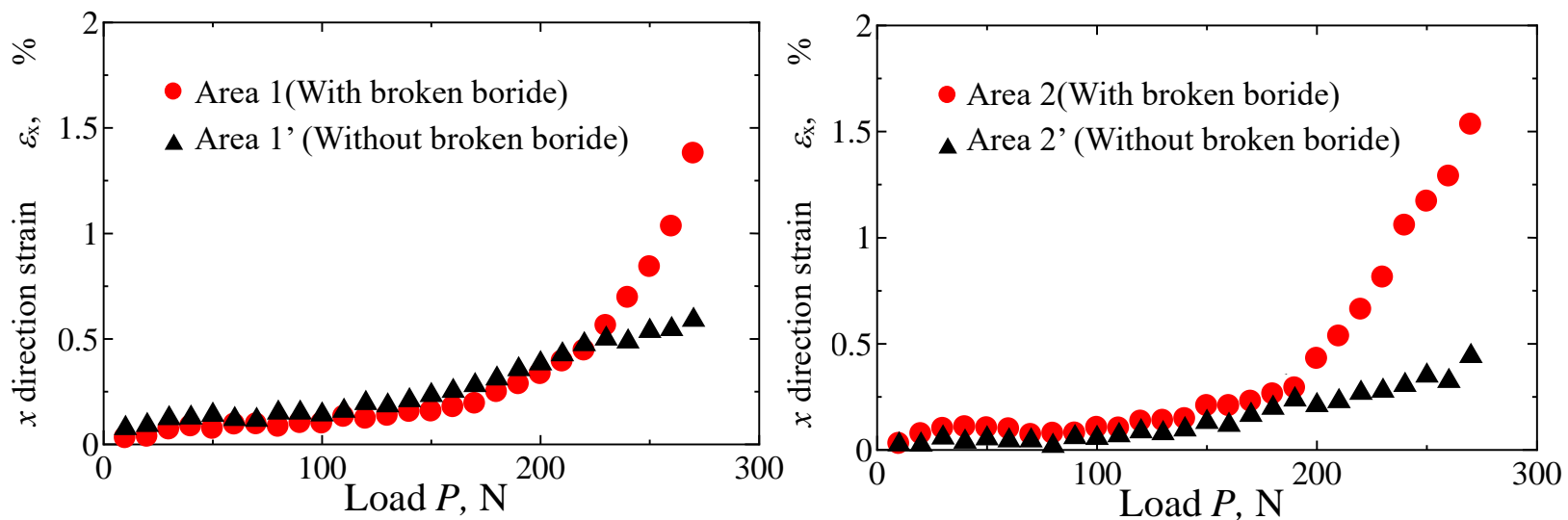

Fig. 7 Variation of $x$-direction strain in area 1 (a) and 2 (b). When the load was small, there was no difference between the strain for the cracked and non-crack areas. When the load became large, the strain of the cracked area was larger than that of the non-cracked area.

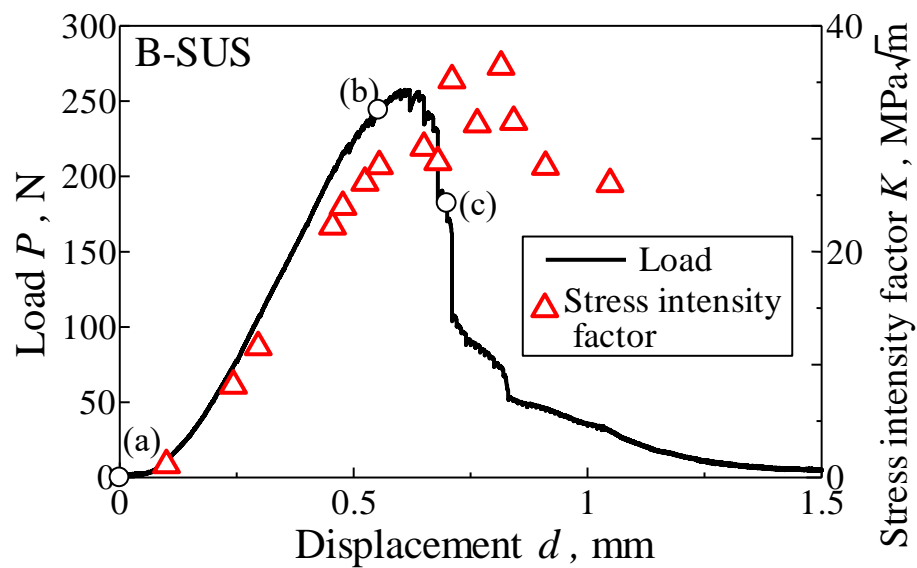

Fig. 8 Fracture toughness test results. The load peaked and then decreased. 
path because the crack grew along the broken borides indicated by the red arrows. After $P=182 \mathrm{~N}$, the crack also propagated along the boride fracture (data not shown).

\subsection{Fatigue crack growth test}

The fatigue crack growth characteristics are presented in Fig. 10. The triangle symbols represent the results of the current study. The open and solid symbols represent the results with and without the small-scale yielding condition, respectively. The circles represent previous results obtained from 4-point-bending tests for a single-edge-notched specimen with $W=14 \mathrm{~mm}, B=6.4 \mathrm{~mm}$ (Miyai et al., 2016). The values obtained for the current study are approximately twice as large as those obtained in the previous study, indicating that the results are similar.

Images of the crack growth are presented in Fig. 11. Figure 11(a) and (b) present overviews of the crack initiated from the notch. The crack propagated with cycling. Figure 11(c) and (d) present close-up images of the crack tip. A few broken borides are observed in front of the crack, and the crack grew linearly. Comparison of the crack for the fracture toughness and fatigue crack growth test results indicates that the crack for the fracture toughness test largely propagated along a zigzag path.
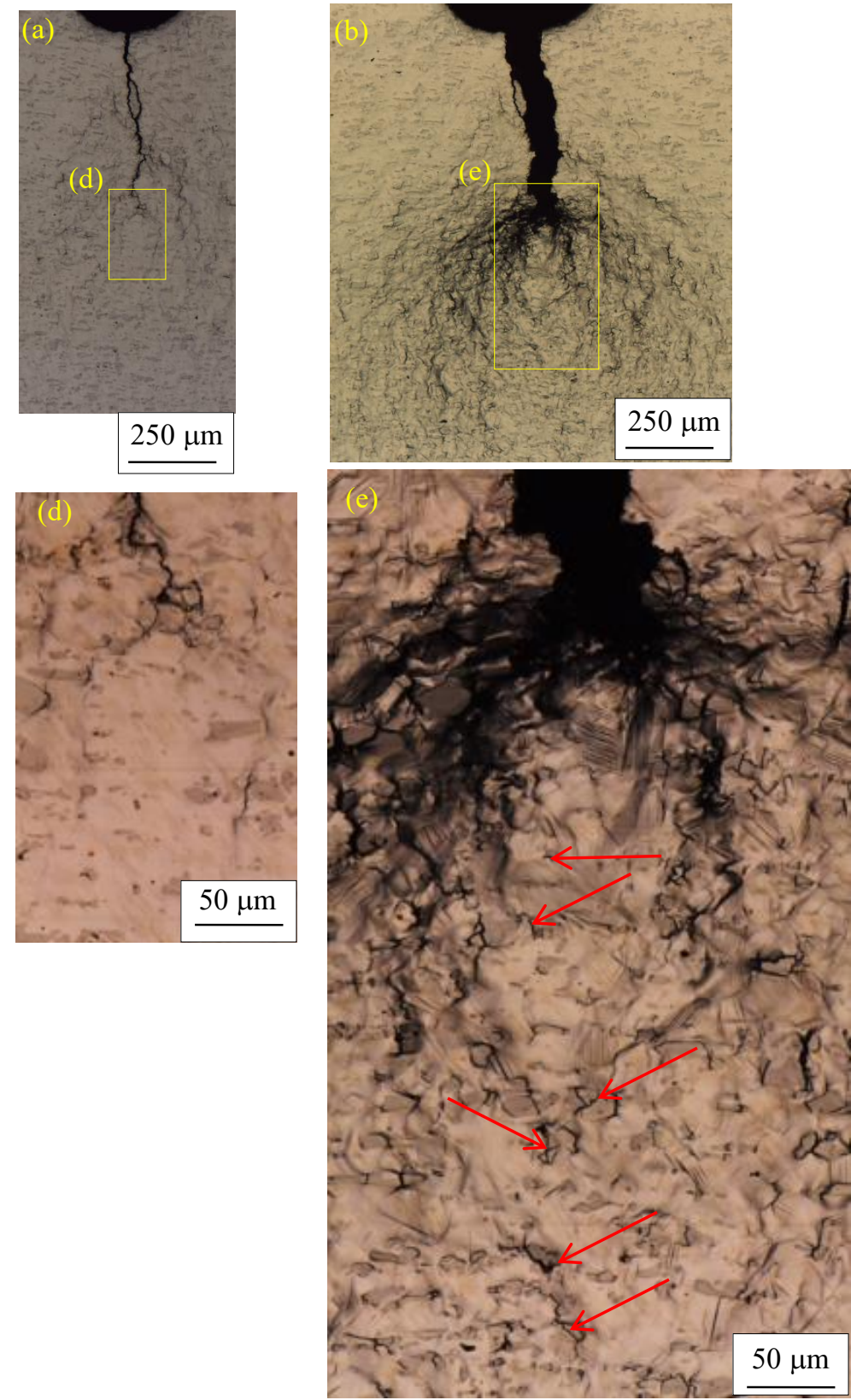
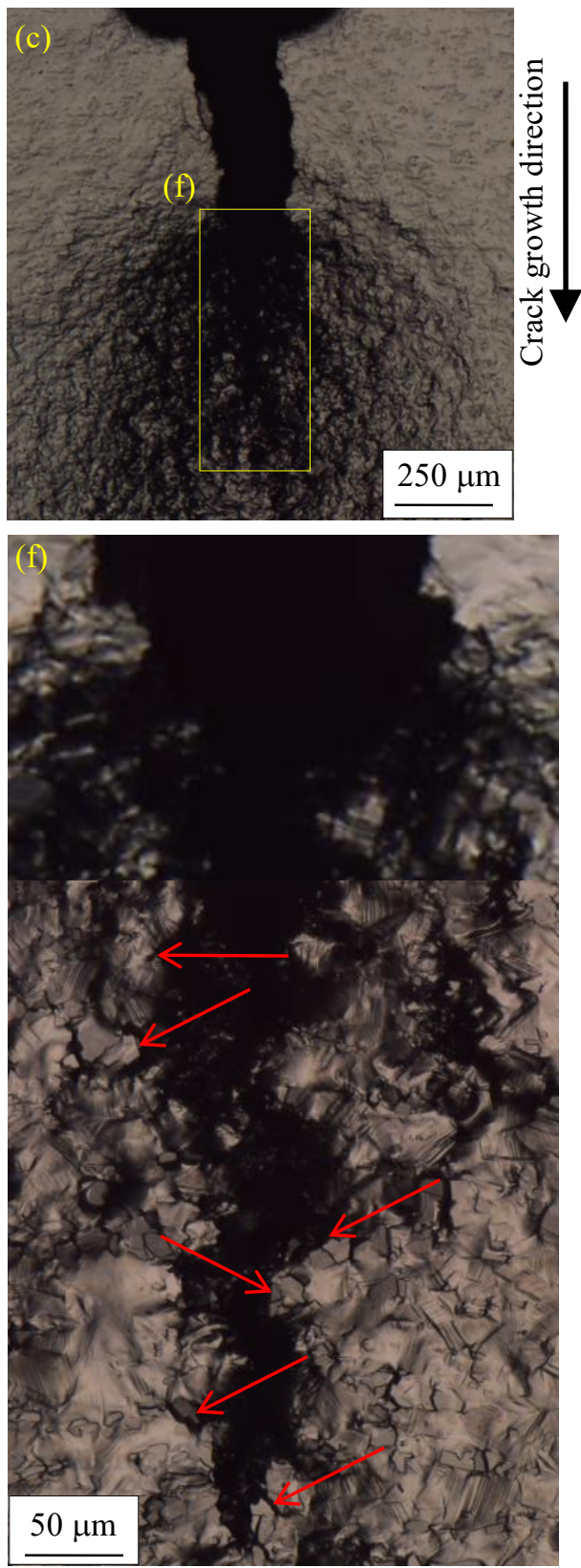

Fig. 9 Observation of crack growth of fracture toughness test at $P=0 \mathrm{~N}$ (a), $244 \mathrm{~N}$ (b), and $182 \mathrm{~N}$ (c). Parts (d), (e), and (f) are close up image of part (a), (b), and (c), respectively. 


\section{Mechanism of crack growth of borated stainless steel}

We discuss the mechanism of the effect of boron addition on static and fatigue crack growth. Figure 12 presents a schematic illustration of the differences in the crack growth mechanisms for the fracture toughness and fatigue crack growth tests. The black, cream and white parts represent the borides, base material and crack, respectively. According to the DIC results, the borides are considered to have broken immediately after yielding. Therefore, the borides were broken in front of the crack tip. The $K$ value was larger for the fracture toughness test than for the fatigue crack growth test. Therefore, many broken borides were present in front of the crack tip for the fracture toughness test, and the crack grew along the broken borides in a zigzag path. Because of this crack growth mechanism, the fracture toughness was

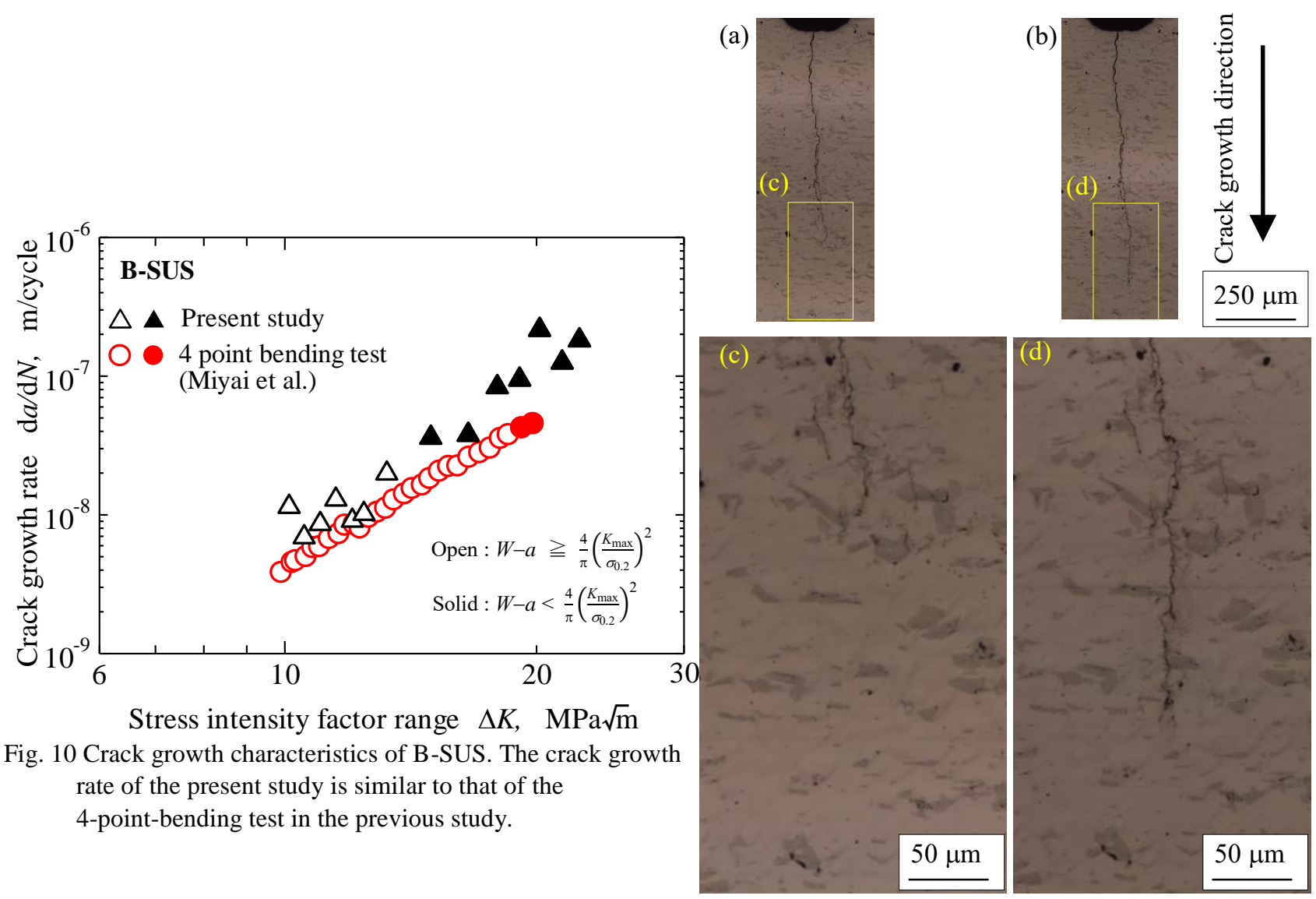

Fig. 11 Observation of fatigue crack growth at $\Delta K=11.0$ (a) and $12.5 \mathrm{MPa} \sqrt{\mathrm{m}}$ (b). (c) and (d) are close-up images of (a) and (b), respectively.

Fracture toughness test

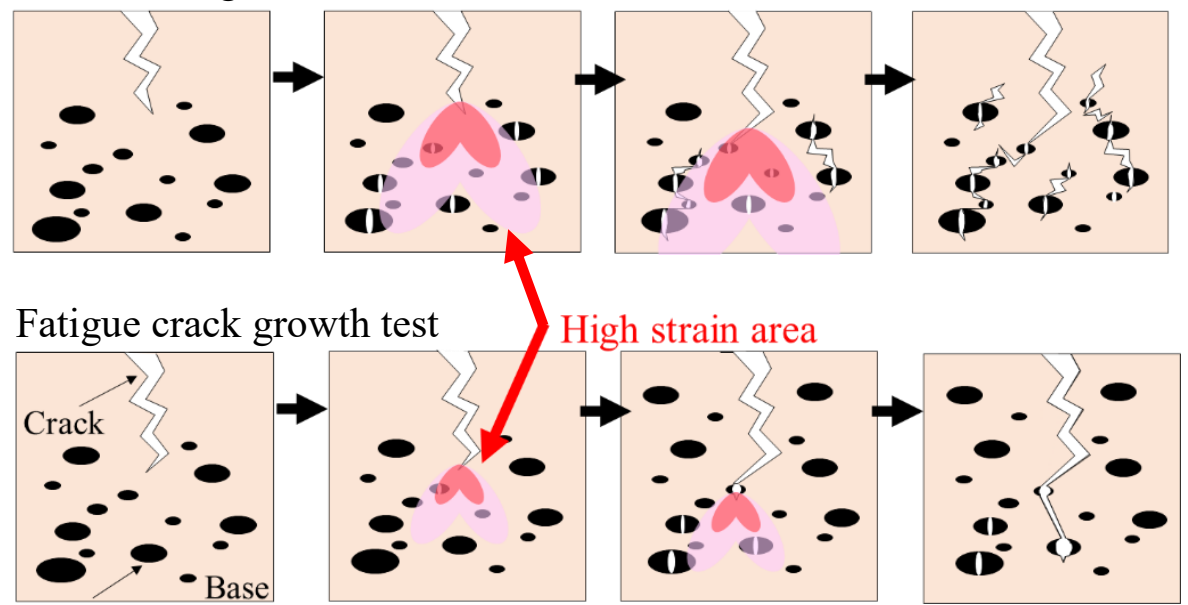

Fig. 12 Schematic illustrations showing differences in crack growth mechanism for fracture toughness and fatigue tests. 
reduced by the boron addition.

However, a few broken borides were observed in front of the crack for the fatigue crack growth test because the $K$ value was smaller than that of the fracture toughness test. Therefore, the crack did not coalesce with broken boride and thus grew linearly. Even if the crack coalesced with broken boride, the area containing broken boride was very small; therefore, the effect of boron addition on the fatigue crack growth was small and the crack grew linearly.

\section{Conclusion}

In this study, we performed in situ laser microscopy observations during tensile, fracture toughness and fatigue crack growth tests of borated stainless steel B-SUS304P-1. Then, we investigated the mechanism of the crack growth. The following conclusions can be drawn.

(1) In the tensile test, there were no large changes in the base material. However, many cracked borides were observed. The strain of boride at fracture was very low compared with the macroscopic elongation of B-SUS. The borides are thought to have broken immediately after macroscopic yielding.

(2) In the fracture toughness test, many broken borides were present in front of the crack tip. Therefore, the crack grew along the broken borides following a zigzag path, and the fracture toughness was thus reduced by the boron addition.

(3) There were only a few broken borides in front of the crack for the fatigue crack growth test. Therefore, the crack grew linearly, and the effect of the boron addition on the fatigue crack growth was small.

\section{Acknowledgments}

We would like to thank Tiffany Jain, M.S., from Edanz Group (www.edanzediting.com/ac) for editing a draft of this manuscript.

\section{References}

American Society for Testing and Materials, Standard test method for measurement of fracture toughness, ASTM standard (2001), ASTM E1820-01.

Doumori, S., Kawauchi, S. and Hiranuma, T., Mechanical properties of B-SUS304P-1 used for basket of transport and storage cask, Transactions of the Japan Society of Mechanical Engineers, Series A, Vol. 76, No. 772 (2010), pp. 308-310 (in Japanese).

Hasunuma, S., Ogawa, T. and Ito, N., Effect of boron addition on the static crack growth mechanism of austenitic stainless steel, Proceedings of the $15^{\text {th }}$ fractography symposium (2018), pp. $43-47$ (in Japanese).

Huang, X., Yu, H., Xu, M. and Zhao, Y., Experimental investigation on microcrack initiation process in nickel-based superalloy DAGH4169, International Journal of Fatigue, Vol. 42 (2012), pp. 153-164.

Kozokenzensei hyouka handbook henshuiinkai hen, Kozokenzensei hyouka handbook (2005), p. 293, Kyoritsu Shuppan (in Japanese).

Miyai, Y., Hotaka, T., Futasugi, T., Hasunuma, S. and Ogawa, T., Effect of boron addition on fatigue crack growth characteristics of austenitic stainless steel, Journal of the Society of Materials Science, Vol. 65, No. 12 (2016), pp. 856-861 (in Japanese).

Takahashi, A., Kobayashi, T. and Toda, H., In-situ SEM study on effect of inclusion particles on fracture behavior in Al-Li system alloy, Journal of Japan Institute of Light Materials, Vol. 49, No. 4 (1999), pp. 166-171 (in Japanese).

Toda, H., Kobayashi, T., Hoshiyama, A. and Takahashi, A., In-situ SEM study on damage evolution at coarse secondary particles in 6061 aluminum alloy, Journal of Japan Institute of Light Metals, Vol. 51, No. 2 (2001), pp. 113-118 (in Japanese).

Yoneyama, S., Basic principle of digital image correlation and procedure for in-plane displacement and strain measurement, Journal of the Japan Society for Composite Materials, Vol. 40, No. 4 (2014), pp. 135-145(in Japanese). 